\title{
The Impact of Chronic Low Back Pain on Daily Occupations: A Qualitative Study in Iranian Context
}

\author{
Fariba Dehkordi', Hamid Reza Khankeh ${ }^{2,3}$, Afsoon Hassani Mehraban ${ }^{4}$, Seyed Ali Hosseini' ${ }^{5}$
}

1. Department of Occupational Therapy, University of Social Welfare and Rehabilitation Sciences, Tehran, Iran

2. Department of Health in Emergency \& Disaster, University of Social Welfare and Rehabilitation Sciences, Tehran, Iran

3. Department of Clinical Science and Education, Karolinska Institutet, Stockholm, Sweden.

4. Rehabilitation Research Center, Department of Occupational Therapy, School of Rehabilitation Sciences, Iran University of Medical Sciences, Tehran, Iran.

5. Social Determinants of Health Research Center, University of Social Welfare and Rehabilitation Sciences, Tehran, Iran.

Crtation: Dehkordi F, Khankeh HR, Hassani Mehraban A, Hosseini SA. The impact of chronic low back pain on daily occupations: A qualitative study in Iranian context. Iranian Rehabilitation Journal. 2016; 14(1):15-22 http://dx.crossref.org/10.15412/J.IRJ.08140103

: http://dx.crossref.org/10.15412/J.IRJ.08140103

Article info:

Received: 29 Jun. 2015

Accepted: 24 Oct. 2015

\section{Keywords:}

Daily occupation, Chronic low back pain, Qualitative study, Occupational performance

\section{ABSTRACT}

Objectives: Low back pain is one of the main health problems which affect many people worldwide. The daily course of life is highly disrupted due to the chronic back pain problem. This study aims to explore the occupational performance of individuals with chronic low back pain

Methods: Fifteen people with chronic low back pain were included in this study using purposeful sampling. The participants were interviewed, and a qualitative content analysis was employed to analyze the data.

Results: The three main resulted themes were: 1) Occupational disturbance because of low back pain; 2) Difficulty in moving around and remaining in any given position; and 3) Permanent mind struggle owing to back pain. People with chronic low back pain experience difficulty in all areas of daily occupation including self-care, work, and leisure, plus having trouble with being physically active and being persistent in certain positions. Furthermore, mind struggle with back pain which implies preoccupation with back pain in addition to fear of movement are other findings of present study.

Discussion: Chronic low back pain greatly influences the daily occupations of individuals Mind struggle with back pain, which implies preoccupation with back pain, in addition to the fear of movement are significant findings of the present study. Occupational therapists can play an important role in re-engagement of people with chronic low back pain in their daily occupations.

\section{* Corresponding Author:}




\section{Introduction}

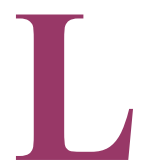

ow back pain is a common problem faced by many individuals. According to a study, about 60 to $80 \%$ of the adult U.S. population suffers from low back pain, thereby, making it the second most common reason people visit the doctor. Approximately $80 \%$ of the world population experience low back pain at some point in their adult life $[1,2]$. Chronic low back pain (CLBP) is a back pain that lasts more than three months and is one of the greatest health problems of industrialized societies [3]. An investigation in the USA showed that, during the years 1992 to 2006, the prevalence of CLBP rose significantly from $3.9 \%$ to $10.2 \%$ [2]. Other studies have reported the prevalence of CLBP to be $23 \%$ in USA with approximately 11 $12 \%$ of the population suffering from this health issue [4]. Another study on Iranian population found out that 29.3\% of its participants suffered low back pain [5].

CLBP is an experience that greatly disrupts the daily lifestyle of an individual [6]. Patients with CLBP report difficulties with a variety of activities [7]. A person with chronic pain will experience both physical and psychological problems. Psychological disturbances, such as depression and anxiety, add to the complexity of chronic pain, limiting the person's ability to engage in meaningful occupations [8]. To our knowledge, no previous studies have yet explored the everyday life condition for CLBP patients in an Iranian population. To fully and holistically address the needs of people living with this problem and in order to support and help those who suffer CLBP in dealing with their daily life, adequate knowledge of their individual experience is very much required.

In order to understand the wide range of problems that can occur with CLBP and its overall impact on everyday life of Iranian people, this study explored the experience and perceptions of people suffering from CLBP. The significance of this work comes from the association that it establishes between CLBP and people's occupations and their daily routines, tasks and activities.

\section{Methods}

A qualitative content analysis was conducted using constant comparative analysis. When new research areas are investigated in an exploratory approach or exploration of a new perspective of a known area is necessary, a qualitative approach is considered as a suitable method. In-depth interviews were done to investigate the personal experiences of those individuals living with CLBP. Content analysis was used for the subjective interpretation of the content of the interview made through a systematic classification process of coding and identification of concepts or patterns $[9,10]$.

Fifteen individuals suffering from CLBP in Tehran, Iran, took part in this study (From July, 2012 to April, 2013). A CLBP sufferer was defined as a person who has pain, muscle tension or stiffness below the costal margin and above the inferior gluteal folds, with or without leg pain (sciatica) for more than 12 weeks [11]. None of the participants had pain in any other part of their body nor had any disease that may affect their occupational performance. The participants were chosen from different physiotherapy clinics and advertisements placed at the University of Social Welfare and Rehabilitation Sciences, Tehran, Iran. The sample size was determined by data saturation. The participants' age range was 28 to 56 years. Pain duration range was 4 months to 25 years. Seven participants had sedentary jobs, and eight had heavy or very heavy jobs [12].

Fifteen interviews were done with 15 participants. Informed consent was obtained from all the participants taking part in the research. All of the interviews were done by the same interviewer, and each interview session was recorded using a voice recorder. The recording was also done with prior consent of the participant. The verbatim transcription of the interview was done followed by content analysis of the text. Data collection was continued until saturation and further data collection failed to contribute any additional information. In-depth interviews were conducted individually in a private and comfortable place chosen by the participant. An interview guide helped to ensure all the main topics that were initially developed by the research team were fully covered. Probing was used when needed in order to clarify the answers. The main questions during in-depth interviews were:

- How do you live with CLBP?/How is your life after CLBP?

- How do you spend a day and what challenges do you face?/Would you describe your daily life for me?

- How do you manage yourself and your daily occupation?

- What change has happened in your occupational life after CLBP?/How has your life been changed by this event?

The interviews were analyzed using qualitative content analysis [10]. A researcher was engaged in data analysis by reading the interviews several times. The data was divided into meaning units. The meaning units were 
condensed, coded, and categorized, leading to the development of themes [10]. The condensation of meaning units was done by reducing the text while still preserving the core. The meaning units were subsequently coded according to the content of the material, and the codes were then labeled by assigning codes on the meaning units. After the coding process, the codes were categorized according to their similarity and differences. Categories and sub-categories were developed, and then the underlying meanings were interpreted as themes. A preliminary set of codes, categories and sub-categories were created from the initial interviews. These codes have been described as the results in this study [9, 10, 13]. This was performed by the same investigator for all the interviews. The MAXQDA10 software (VERBI GmbH, England) was used as a technical aid in the analysis [14, 15]. We listed some examples of data analysis in Table 1.

Ethical approval for the study was obtained from the ethics committees at the University of Social Welfare and Rehabilitation Sciences, Tehran, Iran. Information sheets and consent forms were sent to all interviewees, and they were given an opportunity to ask further questions about the study before participation. All participants were assured anonymity and confidentiality and the right to withdraw at any stage of the study. Signed, informed consent was obtained from all the participants before the interview. For each participant who needed advice about issues which rose at the interview, consultation in the field of rehabilitation was done or some relevant manual books were introduced.

In this study, investigator triangulation was used. Thus, an expert in qualitative research and two other experts in the field of occupational therapy contributed in the supervisory team (Expert check). Moreover, two corresponding researchers who were also involved in some other qualitative projects, reviewed and commented on the emerged data as well (Peer check). Data validation was performed through prolonged engagement with the data. The transcriptions and a summary of the primary results (codes) were reviewed by the participants in order to improve the validity of the same (Member check).

\section{Results}

Fifteen individuals (seven women and eight men) suffering from CLBP participated in this study. The duration of interviews ranged from 17 to 53 minutes, and the participants described their experiences regarding the back pain that they suffered. The result revealed common aspects of do-

Table 1. Example of meaning units, codes, sub-categories and categories.

\begin{tabular}{|c|c|c|c|}
\hline Meaning unit & Code & Subcategory & Category \\
\hline $\begin{array}{l}\text { I'd like watching movie but because of my } \\
\text { back pain I cannot sit for a long time, so I } \\
\text { do it less frequently. }\end{array}$ & $\begin{array}{l}\text { Reducing the time allocated } \\
\text { to leisure activities }\end{array}$ & $\begin{array}{l}\text { CLBP acts as a barrier for } \\
\text { leisure activities }\end{array}$ & $\begin{array}{l}\text { Occupational distur- } \\
\text { bance due to CLBP }\end{array}$ \\
\hline $\begin{array}{l}\text { Before my back problem, I used to spend } \\
\text { my free time on photography but since } \\
\text { taking picture requires frequent changing } \\
\text { of body position, I had to give up. }\end{array}$ & $\begin{array}{c}\text { Elimination of leisure activity } \\
\text { due to LBP }\end{array}$ & & \\
\hline $\begin{array}{l}\text { Back pain is interfering with my work. In } \\
\text { the workplace I cannot lift objects after } \\
\text { painting them, so I have to get help from } \\
\text { my colleagues. }\end{array}$ & $\begin{array}{l}\text { Having trouble with heavy } \\
\text { tasks of work activity }\end{array}$ & $\begin{array}{c}\text { CLBP interfering with work } \\
\text { activities }\end{array}$ & \\
\hline $\begin{array}{l}\text { My evening job was visiting patients in } \\
\text { their homes, but driving for a long dis- } \\
\text { tance to get access to their home would } \\
\text { aggravate my back pain. }\end{array}$ & $\begin{array}{l}\text { Difficulty in driving for job } \\
\text { because of back pain }\end{array}$ & & \\
\hline $\begin{array}{l}\text { I have severe back pain again, I have pain } \\
\text { when lying down, also when getting out } \\
\text { of bed, and now even going to the bath- } \\
\text { room bothers me! Life is really hard for } \\
\text { me. }\end{array}$ & $\begin{array}{l}\text { Having problem with doing } \\
\text { daily routines }\end{array}$ & $\begin{array}{l}\text { Interruption of activity of } \\
\text { daily living due to CLBP }\end{array}$ & \\
\hline $\begin{array}{l}\text { Doing personal affairs, like taking a show- } \\
\text { er, going to the bathroom and sitting on } \\
\text { the table are difficult for me. Specially go- } \\
\text { ing to the bathroom makes my back pain } \\
\text { worse. }\end{array}$ & $\begin{array}{l}\text { Doing personal activities } \\
\text { leading to back pain }\end{array}$ & & \\
\hline
\end{tabular}




\begin{tabular}{|c|c|c|c|}
\hline Meaning unit & Code & Subcategory & Category \\
\hline $\begin{array}{l}\text { Back pain prevents me from running and } \\
\text { doing exercises. I could run well until five } \\
\text { years ago but, now I cannot. }\end{array}$ & $\begin{array}{l}\text { Prevented running and doing } \\
\text { exercise secondary to BP }\end{array}$ & $\begin{array}{l}\text { Limitation of physical } \\
\text { activity }\end{array}$ & $\begin{array}{l}\text { Difficulty in moving } \\
\text { around and remaining in } \\
\text { positions }\end{array}$ \\
\hline $\begin{array}{l}\text { I really like to do sports the same as oth- } \\
\text { ers. Before back pain, I did Kung Fu and } \\
\text { Power Lifting. I do like to do them again, } \\
\text { but I can't since my back pain prevents } \\
\text { me from doing these activities. }\end{array}$ & $\begin{array}{l}\text { Discarding sport activities } \\
\text { despite being interested in } \\
\text { them }\end{array}$ & & \\
\hline $\begin{array}{l}\text { In regular sitting I have no pain, but if it } \\
\text { lasts for a long time, I'll have back pain } \\
\text { again. Naturally, lying and standing for a } \\
\text { long time leads to pain too. }\end{array}$ & $\begin{array}{l}\text { Being in every position for a } \\
\text { long time leads to low back } \\
\text { pain }\end{array}$ & $\begin{array}{l}\text { Problem in being in sus- } \\
\text { tained positions }\end{array}$ & \\
\hline $\begin{array}{l}\text { It is only possible for me to sit with my } \\
\text { back rested. I put a stool in the bathroom } \\
\text { while taking a bath, and I always sit on it. } \\
\text { After taking a shower which lasts from } \\
\text { half an hour to one hour, I feel stiff. }\end{array}$ & $\begin{array}{l}\text { Remaining in seated position, } \\
\text { leads to back stiffness }\end{array}$ & & \\
\hline $\begin{array}{l}\text { Sometimes when I decide to move, I have } \\
\text { a strange feeling as if my back pain is go- } \\
\text { ing to start again. This feeling is always } \\
\text { with me. }\end{array}$ & $\begin{array}{l}\text { Back pain anticipation before } \\
\text { doing movements }\end{array}$ & $\begin{array}{l}\text { Preoccupation with back } \\
\text { pain }\end{array}$ & $\begin{array}{l}\text { Permanent mind struggle } \\
\text { with back pain }\end{array}$ \\
\hline $\begin{array}{l}\text { I always assume that there is a defect in } \\
\text { my back and I must take care of it. This } \\
\text { means that regardless of pain, fear of } \\
\text { pain is another concern for me. For ex- } \\
\text { ample, while sitting, because of this fear, } \\
\text { I change my position every five to six min- } \\
\text { utes. }\end{array}$ & Permanent care of the back & & \\
\hline $\begin{array}{l}\text { I have a fear when I am sitting, a fear } \\
\text { of bending. Consequently, I try to sit in } \\
\text { cross-legged position without bending } \\
\text { over. }\end{array}$ & $\begin{array}{l}\text { Fear of pain affecting move- } \\
\text { ment pattern }\end{array}$ & Fear of movement & \\
\hline $\begin{array}{l}\text { I believe that, if I move objects, I'Il be in } \\
\text { pain for ten days. So, this thought is affect- } \\
\text { ing everything. }\end{array}$ & $\begin{array}{l}\text { Pain prediction, preventing } \\
\text { motion }\end{array}$ & & \\
\hline
\end{tabular}

ing daily occupations while having CLBP. The three main resulted themes were: 1) Occupational disturbance because of CLBP including CLBP as a barrier for leisure activities, interference with work activities and interruption of activities of daily living; 2) Difficulty in moving around and remaining in certain positions including limitation of physical activity and problem in being in sustained position; and 3) Permanent mind struggle with back pain including preoccupation with back pain and fear of movement.

\section{Occupational disturbance due to CLBP}

\section{CLBP acts as a barrier for leisure activities}

The participants with CLBP stated the inability to perform leisure activities as one of their performance problems. Leisure activities were personal activities that had a significant impact on the personal level of satisfaction and quality of life. In many cases, one had to withhold from his/her interests or do it less often because of back pain issues. Two of the participants' descriptions were as follows:

"I'd like watching movie but because of my back pain I cannot sit for a long time, so I do it rarely" (P2).

"Before my back problem, I used to spend my free time on photography but since taking picture require frequent changing of body position, I had to give up" (P1).

\section{CLBP interfering with work activities}

One of the biggest challenges of this group of participants was doing activities and tasks associated with their work or in the job. However, the challenges varied depending on the type of job. Although doing activities related to heavy jobs was more challenging, sedentary jobs had also problems of their own. In this regard, two of the participants' descriptions were as follows: 
"Back pain is interfering with my work. In the workplace I cannot lift objects after painting them, so I have to get help from my colleagues" (P14).

"My evening job was visiting patients in their homes, but driving for a long distance to get access to their home would aggravate my back pain" (P2).

\section{Interruption of activities of daily living due to CLBP}

Doing daily routines such as toileting, showering, dressing, sleeping, and so on are basic needs of every human being. However, a person with back pain may face difficulties in meeting these requirements. Showering and going to the bathroom, especially using the Iranian style, were the most frequent daily activities that the people with CLBP complained about. Two of the participants' descriptions were as follows:

"I have severe back pain again, I have pain when lying down, also when getting out of bed, and now even going to the bathroom bothers me! Life is really hard for me" (P9).

"Doing personal affairs, like taking a shower, going to the bathroom and sitting on the table are difficult for me. Specially going to the bathroom makes my back pain worse" (P14).

Difficulty in moving around and remaining in positions

\section{Limitation of physical activity due to CLBP}

Most participants stated that they had difficulty in doing certain movements and being physically active. Running and doing sports-related activities and exercises were among the most challenging movements. In this sense, two of the participants' descriptions were as follows:

"Back pain prevents me from running and doing exercises. I could run well until five years ago but, now I cannot" (P13).

"I really like to do sports the same as others. Before back pain, I did Kung Fu and Power Lifting. I do like to do them again, but I can't since my back pain prevents me from doing these activities" (P10).

\section{Problem in being in sustained position}

Sustained and static positions were frequently mentioned as the most unbearable positions by the participants. They stated that they had difficulty in remaining seated and standing for a long time owing to the aggravation of back pain. Therefore, they had to change their position repeatedly. Two of the participants' descriptions were as follows:
"In regular sitting I have no pain, but if it lasts for a long time, I'll have back pain again. Naturally, lying and standing for a long time leads to pain too" (P6).

"It is only possible for me to sit with my back rested. I put a stool in the bathroom while taking a bath, and I always sit on it. After taking a shower which lasts from half an hour to one hour, I feel stiff" (P14).

\section{Permanent mind struggles with back pain}

\section{Usual preoccupation with back pain}

The participants described that they often thought about their back pain and could not forget about it. In other words, they expected to have back pain while doing every occupation or movement even if it might not occur during all situations. This permanent focus on back pain was an important barrier for doing occupations and activities. In this regard, two of the participants' descriptions were as follows:

"Sometimes when I decide to move, I have a strange feeling as if my back pain is going to start again. This feeling is always with me" (P15).

"I always assume that there is a defect in my back and I must take care of it. This means that regardless of pain, fear of pain is another concern for me. For example, while sitting, because of this fear, I change my position every five to six minutes" (P11).

\section{Fear of movement}

Feeling anxious and stressed and the fear of movement was another problem of the participants. Since their pain was often the result of movement, they expected to have pain whenever they decided to move. Therefore, sometimes they took unusual ways of doing tasks and activities. Two of the participants' descriptions were as follows:

"I have a fear when I am sitting, a fear of bending. Consequently, I try to sit in cross-legged position without bending over" (P5).

"I believe that, if I move objects, I'll be in pain for ten days. So, this thought is affecting everything” (P8).

\section{Discussion}

This study describes some aspects of performing daily occupational tasks in those suffering from CLBP. The study brings some new understandings regarding the extent to which occupational performance is affected by CLBP. 
The study shows that CLBP has several disturbing impacts on the occupational life of individuals suffering from it. Based on the experiences and perceptions of the participants in this study, three categories were explored, including occupational disturbance due to CLBP, difficulty in moving around and remaining in certain positions, and permanent mind struggle with back pain. The novel aspects of the present study dealt with mind struggle and preoccupation of the sufferers with back pain, making both these aspects the prominent findings of this study that distinguished it from other studies.

In accordance with the present study, previous studies had also emphasized on chronic pain as a barrier for doing occupations [6, 16-19]. However, the occupational therapy perspective was the main focus of this present study. This study was specifically conducted on people with CLBP and not in all chronic pain sufferers.

Occupational disturbance because of CLBP was a significant finding, which included CLBP as a barrier for leisure activities of the individuals suffering from it, in agreement with the previous studies. Moreover, CLBP can lead to the reduction or exclusion of leisure activities from individuals' lives. Spenkelink and colleagues have reported that their participants needed all their capacity to perform the tasks during the day and as a consequence had less capacity left for their leisure time in the evening [20]. Another study found that physical limitations and financial barriers restricted the engagement in leisure activities for individuals with CLBP [21].

CLBP can interfere in work activities, specifically involving heavy lifting or requiring heavy manual labor or handling multiple jobs, because such workload with heavy physical demands cannot be tolerated by the individuals suffering from CLBP. Several previous studies have only investigated the varied workplace challenges and barriers to return to work rather than understanding the experiences related to CLBP $[6,18]$. Meanwhile, many studies have reported sickness absence from work as a consequence of back pain [1, 3, 7, 9-13].

Consistent with previous studies, our participants reported problems faced when carrying out their daily routines. Daily routines are commonly considered as personal activities that are frequently performed and are very important for the person. Unlike those previous studies that have only mentioned the overall effect of low back pain on performing the daily activities, the results of this study have emphasized on both the activity of daily living (toileting, showering, etc.) and instru- mental activity of daily living (e.g. driving). Both activities require attention in this group of people.

Few studies have found trouble with walking in those suffering from back pain, including reduced walking speed, especially in the evening hours [20]. In the present study, none of the participants complained about difficulty in walking, but limitation of physical activity such as running or doing sports activities was repeatedly expressed. Verbunt and colleagues reported that the physical activity level of their patient and control groups did not differ significantly, which is inconsistent with our findings [22]. The inability to remain in sustained positions such as sitting or standing was another complaint of all our participants, which is in agreement with other studies [20, 23]. The majority of people with low back pain had difficulty in remaining in certain positions for a long time.

Aside the physical problems of back pain, mind struggle with back pain had a disturbing impact on performing the daily occupations. Thus, preoccupation with back pain before movement and doing occupations itself acts as a barrier for occupational performance. Moreover, frustration and difficulty in engagement in daily activities and occupations are caused because of the excessive attention to pain [24]. Few studies denoted this as a mental challenge. Also, the fear of movement was considered as a part of this mental challenge. Since people with CLBP most often experience movement-related pain, the fear of movement gradually arises. This fear of movement is a well-known issue particularly in psychology, generally referred to as kinesiophobia. It can eventually lead to movement avoidance behaviors, which are the main cause of physical deconditioning syndrome [25-29].

\section{Conclusion}

CLBP is a problem that many sufferers have to live with. So, performing daily occupations and keeping up with the occupational life despite having CLBP is one of the critical concerns of people suffering from CLBP. Previous studies showed that occupational limitation and deprivation could result in dissatisfaction and depression $[30,31]$. According to the findings of this study, people with CLBP experienced difficulty in all areas of occupational performance including self-care, work and leisure, in addition to having trouble with moving around and remaining in static or sustained positions. To our knowledge, our last finding dealing with mind struggle with back pain was only addressed as a cause for low back pain by former studies instead of its consequence. 
Furthermore, this mind struggle eventually implies preoccupation with back pain in addition to the fear of movement, which seems to be more comprehensive than kinesiophobia or attention to pain that have been described in previous studies. As few studies have mentioned this problem, we suggest this issue to be investigated in future. It is worth noting that the findings of the present study can only be applied in similar contexts and cultures and should not be generalized to CLBP sufferers worldwide.

This was the first study in an Iranian heterogeneous population regarding CLBP sufferers' experiences in their daily occupations. Further studies in homogenous subgroups of CLBP individuals are recommended in order to find out the occupational performance characteristics of each subgroup. Exploring the process of living with CLBP is also recommended.

\section{Acknowledgments}

The authors would like to appreciate all participants for their contribution to this study. The authors also wish to thank Mr. Mehdi Rezaee and Mrs. Mitra Khalafbeigi for their sincere cooperation in peer check of the data. The article is extracted from Mr. Fariba Dehkordi's master thesis in the department of occupational therapy, University of Social Welfare and Rehabilitation Sciences, Tehran, Iran.

\section{Conflict of Interests}

The authors declared no conflict of interests.

\section{References}

[1] Diamond S, Borenstein D. Chronic low back pain in a working-age adult. Best Practice \& Research Clinical Rheumatology. 2006; 20(4):707-20.

[2] Freburger JK, Holmes GM, Agans RP, Jackman AM, Darter JD, Wallace AS, et al. The rising prevalence of chronic low back pain. Archives of Internal Medicine. 2009; 169(3):251-58.

[3] Andersson GB. Epidemiological features of chronic lowback pain. Lancet. 1999; 354(9178):581-85.

[4] Balagué F, Mannion AF, Pellisé F, Cedraschi C. Nonspecific low back pain. The Lancet [Internet]. Elsevier BV; 2012 Feb;379(9814):482-91. Available from: http://dx.doi. org/10.1016/s0140-6736(11)60610-7.

[5] Biglarian A, Seifi B, Bakhshi E, Mohammad K, Rahgozar $\mathrm{M}$, Karimlou M, et al. Low back pain prevalence and associated factors in Iranian population: findings from the na- tional health survey. Pain Research and Treatment. 2012; 2012:653060. doi: 10.1155/2012/653060

[6] Bunzli S, Watkins R, Smith A, Schütze R, O'Sullivan P. Lives on hold: a qualitative synthesis exploring the experience of chronic low-back pain. The Clinical Journal of Pain. 2013; 29(10):907-16. doi: 10.1097/AJP.0b013e31827a6dd8

[7] Walsh DA, Kelly SJ, Johnson PS, Rajkumar S, Bennetts K. Performance problems of patients with chronic low-back pain and the measurement of patient-centered outcome. Spine. 2004; 29(1):87-93.

[8] Fisher GS, Emerson L, Firpo C, Ptak J, Wonn J, Bartolacci G. Chronic pain and occupation: an exploration of the lived experience. American Journal of Occupational Therapy. 2007; 61(3):290-302.

[9] Elo S, Kyngäs H. The qualitative content analysis process. Journal of Advanced Nursing. 2008; 62(1):107-15. doi 10.1111/j.1365-2648.2007.04569.x

[10] Graneheim UH, Lundman B. Qualitative content analysis in nursing research: concepts, procedures and measures to achieve trustworthiness. Nurse Education Today. 2004; 24(2):105-12.

[11] Crowe M, Whitehead L, Jo Gagan M, Baxter D, Panckhurst A. Self-management and chronic low back pain: a qualitative study. Journal of Advanced Nursing. 2010; 66(7):1478-86. doi: 10.1111/j.1365-2648.2010.05316.x

[12] Key GL. Industrial therapy. Virginia: Mosby; 1995.

[13] Malterud K. Qualitative research: standards, challenges, and guidelines. Lancet. 2001; 358(9280):483-88

[14] Humble ÁM. Qualitative data analysis software: a call for understanding, detail, intentionality, and thoughtfulness. Journal of Family Theory \& Review. 2012; 4(122):122-37.

[15] Schönfelder W. CAQDAS and qualitative syllogism logicNVivo 8 and MAXQDA 10 compared. Forum: Qualitative Social Research. 2011; 12(1):40.

[16] Aegler B, Satink T. Performing occupations under pain the experience of persons with chronic pain. Scandinavian Journal of Occupational Therapy. 2009; 16(1):49-56. doi: $10.1080 / 11038120802512425$

[17] Satink T, Winding K, Jonsson H. Daily occupations with or without pain: dilemmas in occupational performance Occupation, Participation \& Health. 2004; 24:144-50. doi: $10.1177 / 153944920402400404$

[18] Snelgrove S, Liossi C. Living with chronic low back pain a metasynthesis of qualitative research. Chronic Illness. 2013; 9(4):283-301. doi: 10.1177/1742395313476901

[19] Corbett M, Foster NE, Ong BN. Living with low back painStories of hope and despair. Social Science \& Medicine. 2007; 65(8):1584-594

[20] Spenkelink CD, Hutten MM, Hermens HJ, Greitemann BO. Assessment of activities of daily living with an ambulatory monitoring system: a comparative study in patients with chronic low back pain and nonsymptomatic controls. Clinical Rehabilitation. 2002; 16(1):16-26.

[21] Ashby S, Fitzgerald M, Raine S. The impact of chronic low back pain on leisure participation: implications for occupa- 
tional therapy. The British Journal of Occupational Therapy. 2012; 75(11):503-08.

[22] Verbunt JA, Huijnen IPJ, Köke A. Assessment of physical activity in daily life in patients with musculoskeletal pain. European Journal of Pain. 2009; 13(3):231-42. doi: 10.1016/j. ejpain.2008.04.006

[23] De Souza LH, Frank AO. Experiences of living with chronic back pain: the physical disabilities. Disability \& Rehabilitation. 2007; 29(7):587-96

[24] Viane I, Crombez G, Eccleston C, Devulder J, De Corte W. Acceptance of the unpleasant reality of chronic pain: effects upon attention to pain and engagement with daily activities. Pain. 2004; 112(3):282-88

[25] Crombez G, Vlaeyen JW, Heuts PH, Lysens R. Pain-related fear is more disabling than pain itself: evidence on the role of pain-related fear in chronic back pain disability. Pain. 1999; 80(1-2):329-39.

[26] Picavet HSJ, Vlaeyen JW, Schouten JS. Pain catastrophizing and kinesiophobia: predictors of chronic low back pain American Journal of Epidemiology. 2002; 156(11):1028-034

[27] Roelofs J, Peters ML, Vlaeyen JWS. Selective attention for pain-related information in healthy individuals: the role of pain and fear. European Journal of Pain. 2002; 6(5):331-9. doi: 10.1016/S1090-3801(02)00021-6

[28] Swinkels-Meewisse IEJ, Roelofs J, Verbeek ALM, Oostendorp RAB, Vlaeyen JWS. Fear of movement/(re)injury, disability and participation in acute low back pain. Pain. 2003; 105(1):371-79. doi: 10.1016/S0304-3959(03)00255-0

[29] Vlaeyen J, Crombez G. Fear of movement/(re)injury, avoidance and pain disability in chronic low back pain patients. Manual therapy. 1999; 4(4):187-95. doi: 10.1054/ math.1999.0199

[30] Klinger L, Spaulding SJ, Polatajko HJ, MacKinnon JR, Miller L. Chronic pain in the elderly: occupational adaptation as a means of coping with osteoarthritis of the hip and/or knee. Clinical Journal of Pain. 1999; 15(4):275-83.

[31] Slade SC, Molloy E, Keating JL. Listen to me, tell me': a qualitative study of partnership in care for people with nonspecific chronic low back pain. Clinical Rehabilitation. 2009; 23(3):270-80. doi: 10.1177/0269215508100468 